\title{
Organization of the Spermatozoon of Agriolimax reticulatus, the Grey Field Slug (Pulmonata, Stylommatophora)
}

\author{
Christopher J. Bayne* \\ University College of North Wales, Marine Science Laboratories, Menai Bridge, \\ Anglesey, U.K.
}

Received August 25, 1969

\begin{abstract}
Summary. Mature spermatozoa from the seminal vesicles of adult Agriolimax reticulatus have been studied by means of phase contrast and electron microscopy; sperm were either live, or sectioned or mounted whole and shadowed with gold. The cell is of the typical pulmo. nate sperm type with a simple acrosome and a spiral nucleus comprising the head, and a tail which is ensheathed along its entire length by mitochondrion. The 9 peripheral fibrils of the axial complex show no indication of a double nature. Within the spermatheca or "gametolytic gland" breakdown of sperm occurs; the nucleus and axial fibre bundle of the flagellum survive the longest. The complexity of the flagellum and the relative simplicity of the acrosome are discussed in light of the ecology of the spermatozoa. Many problems concerning the functional physiology of the sperm organelles remain to be investigated.
\end{abstract}

Key-Words: Pulmonata - Stylommatophora - Agriolimax reticulatus -- Spermatozoa.

A vast increase in the number of ultrastructural studies on invertebrate sperm has taken place in the past ten years. Out of this have come several useful papers on gastropod sperm (Grassé, Carasso and Favard, 1956; Rebhun, 1957; Kaye, 1958; Gall, 1961; André, 1962; Yasuzumi, 1962 ; Barth and Oliveira, 1964; Tahmisian, 1964 ; Personne and André, 1964; Galangau and Tuzet, 1966 ; Thompson, 1966 ; Tuzet and Galangau, 1967; Walker and Maegregor, 1968; Anderson and Personne, 1969a, $\mathrm{b}$; Personne and Anderson, 1969; Thompson and Bebbington, 1969); two describe electron microscope studies of the sperm tail of Agriolimax (Bradfield, 1955; Tuzet and Galangau, 1967). The most obvious point to emerge from these publications is the very close similarity between opisthobranch and pulmonate sperms (Franzen, 1955 ) and the practically identical nature of all pulmonate sperm. This situation may discourage research of this kind since researchers will fear that they will find nothing new and perhaps nothing sufficiently noteworthy to justify publication. This would be unfortunate since there is still much to be learned about the ultrastructure of these cells. Some of these problems are mentioned later.

Agriolimax reticulatus, in common with all pulmonate gastropods, is hermaphrodite. Experiments in this laboratory show that the power of self-fertilization is very limited in this species relative to several other pulmonates. The ova of this slug come into contact with numerous apparently mature sperm soon after the ova are released from the gonad. These sperm are the animal's own, and appear to be morphologically mature. However, they do not normally fertilize

* Present address: Museum of Zoology. The University of Michigan. Ann Arbor, Michigan, U.S.A., 48104. 
the eggs; sperm are apparently rarely capable of fertilization until they have been transferred at copulation. There is thus possibly a process of physiological maturation following transfer. This process will be the subject of intensive research. This present project was undertaken as a preliminary to such a study of sperm physiology in this and other gastropods.

\section{Material and Methods ${ }^{1}$}

A complete study of the functional morphology of sperm would ideally include ultrastructural studies of spermatogenesis, mature sperm, and the destiny of sperm organelles in fertilization (Pasteels, 1965). In the present study sperm from only the seminal vesicle and spermatheca have been examined. The interpretation of the micrographs was greatly facilitated by a study of previous publications on sperm ultrastructure which have included spermatogenesis.

Slugs were collected in the gardens of the laboratory. They were dissected within a day of capture, and the hermaphrodite duct (= seminal vesicle) and sometimes spermatheca were quickly removed (Bayne, 1967). They were either transferred directly to fixative at $4^{\circ} \mathrm{C}$, or with some hermaphrodite ducts the sperm were mixed into a suspension in slug body fluids and suspended on collodion film on copper grids, then dried. These were either viewed directly in the electron microscope, or shadowed with gold (Kay, 1965) prior to being viewed.

Four fixation methods described by Pease (1964), were used: (i) 12 hours in glutaraldehyde in phosphate buffer; (ii) $0.5-2$ hours in Palade's osmium fixative; (iii) glutaraldehyde fixation followed by osmium; (iv) 12 hours fixation in $\mathrm{KMnO}_{4}$. The fixatives were kept at $4 \pm 1^{\circ} \mathrm{C}$. Dehydration after permanganate fixation was by transfer to acetone: ethanol $(95: 5)-10$ minutes, acetone : ethanol $(50: 50)-10$ minutes, absolute ethanol $2 \times 10$ minutes, then propylene oxide -10 minutes. The other fixatives were followed by 10 minutes in each of the following: tap water, $50 \%$ ethanol, $90 \%$ ethanol, absolute ethanol, absolute ethanol, propylene oxide.

The tissues were embedded in Araldite and sectioned on a Cambridge ultratome using glass knives. The sections were taken up on copper grids, and stained with either uranyl acetate, or uranyl acetate - lead citrate, or lead citrate, or potassium permanganate. An A.E.I. EM $6 \mathrm{~B}$ microscope was used to study the material at magnifications up to 30,000 .

Live sperm were studied under phase contrast and compared with sperm in $1 \mu$ sections of Araldite blocks. This showed that the preparatory process had apparently not damaged the material.

\section{Results}

\section{Structure of the Mature Hermaphrodite Duct Sperm}

\section{Overall Dimensions and Morphology}

The sperm is of the typical pulmonate type (Franzen, 1955), being composed essentially of a head (acrosome + nucleus), and a flagellum (axial fibre bundle ensheathed along its entire length by a mitochondrial sleeve). The "middle piece" thus constitutes the entire sperm tail or flagellum. The mature spermatozoon measures $140 \pm 5 \mu$ in length; the head occupies $8 \mu$ of which $6 \pm 0.2 \mu$ is nucleus and $2 \pm 0.2 \mu$ is acrosome. The flagellum measures about $132 \mu$.

The sperm are often coiled up (Fig. 1) on removal from the hermaphrodite duct seminal vesicle, but they soon uncoil with explosive suddenness after leaving the seminal vesicle.

1 Research facilities and funds were generously provided for me by Professor D. J. Crisp, F.R.S. Dr. J. Nott kindly gave his time to instruct me in electron microscope technique. To these persons I wish to express my gratitude. 


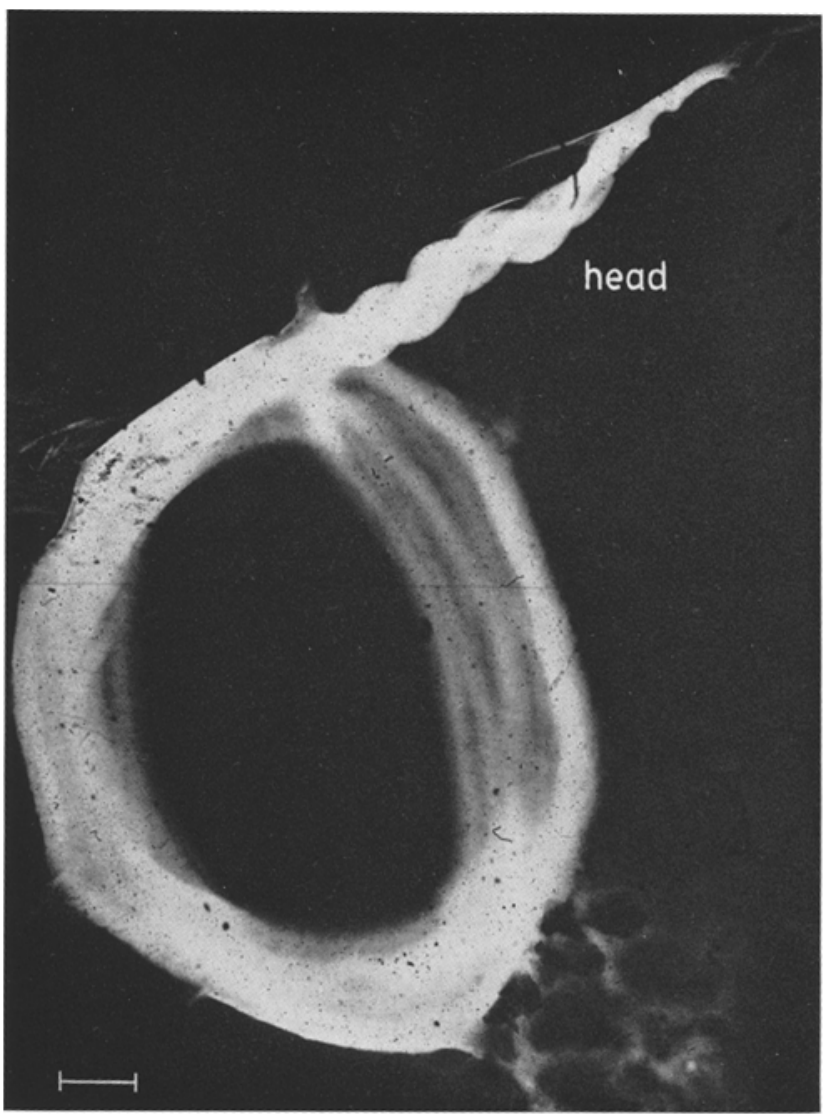

Fig. 1. Unshadowed whole specimen of a coiled spermatozoon from the seminal vesicle. Scale $=1$ micron

The head has the form of a triple corkscrew which spirals twice in the length of the head. Of the 3 ridges composing the spiral complex, two (ridges 1 and 3 ) are more closely associated as a parallel pair (Fig. 2) and the third (ridge 1) is distinct as described below. The anterior part of the head is constituted by ridge 1 being straight and lying in the mid-line, with the pair of ridges 2 and 3 beginning to spiral round in a clockwise direction as viewed from in front of the sperm. At the completion of the first spiral (the middle of the head), ridge 1 begins to spiral also. The three ridges which compose the spiral head extend posteriorly from the head as ridges of "middle piece" material (mitochondrial derivative). Ridge 1 is characterized by being "hollow" in this extensive region (Fig. 3, $C-F$ ). In the head, ridges 2 and 3 are higher than ridge 1 , but this situation is reversed at the junction of head and "tail". Ridges 2 and 3 soon decrease until they are indistinguishable after $13-14 \mu$ of the flagellum (Fig. 3, $E$ ). The "hollow" nature of ridge 1 persists, however, and this ridge is visible externally for about half the length of the flagellum $(70 \mu)$. The hollow helix continues down the flagellum beyond the point where the ridge over it disappears (Fig. 3, $F$ ) but the helix itself 

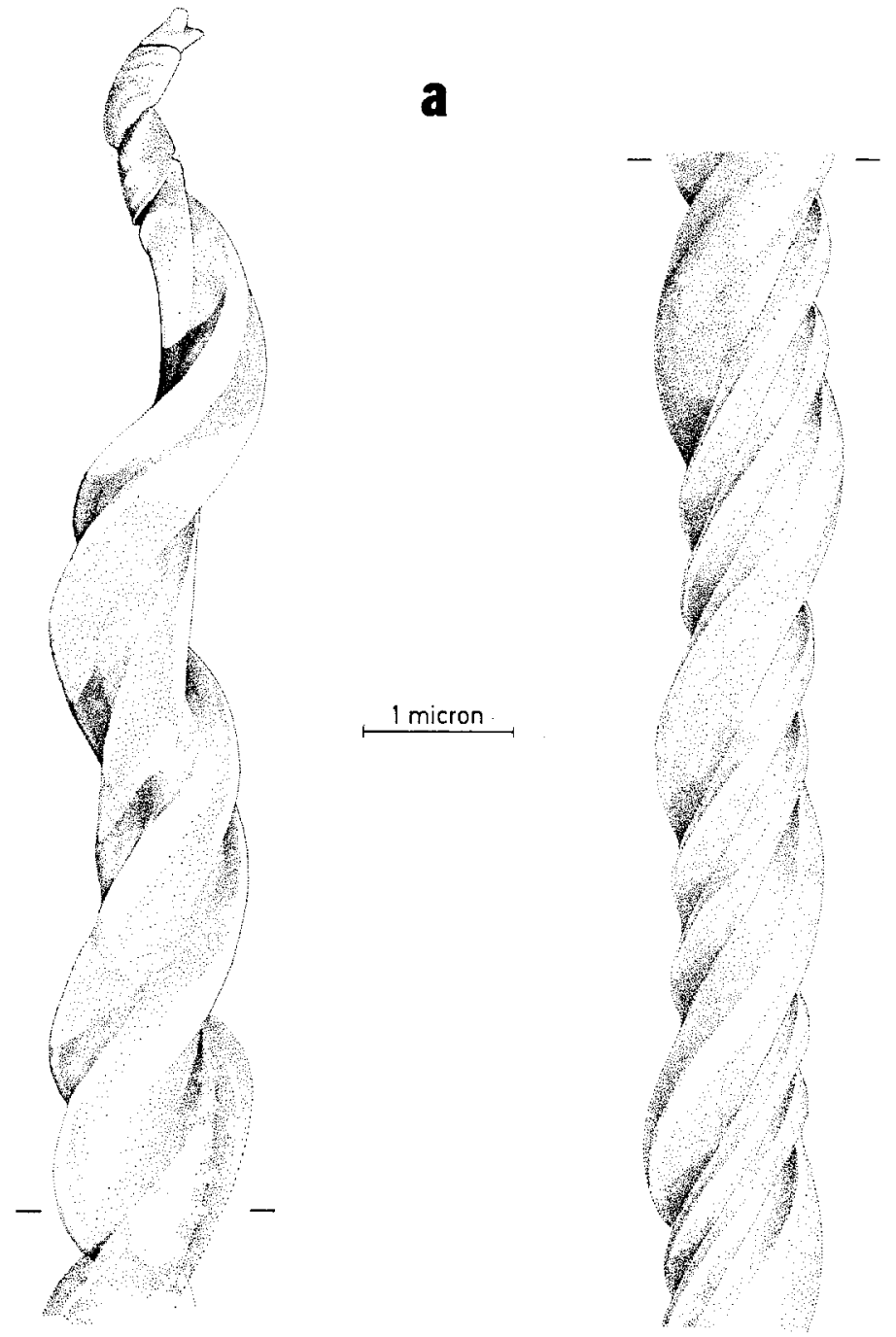

Fig. $2 a-c$. Anterior end of the mature spermatozoon. Seale $=1$ micron. a Drawing to show the 3-dimensional form of the head and first part of the flagellum. Based on shadowed specimens; illustration by John Tottenham. b Unshadowed sperm to illustrate the acrosomal extension of the head, and the different electron densities of the nuclear and mitochondrial materials. c Gold-shadowed specimen. The main mitochondrial helix (1) is slightly more compressed than it probably is in live specimens

does not extend to within more than about $15 \mu$ of the flagellar tip. In this region, therefore, the two layers of mitochondrial material (see later) lie perfectly concentrically (Fig. 3, $G$ ).

\section{Ultrastructure}

Head (Fig.2). The nuclear material is present in a homogeneous state, as is typical of fully mature sperm heads (Rebhun, 1957; Walker and Macgregor, 1968). The substance is heavily stained by uranyl acetate (Figs. 3, 4a) but is not at all 


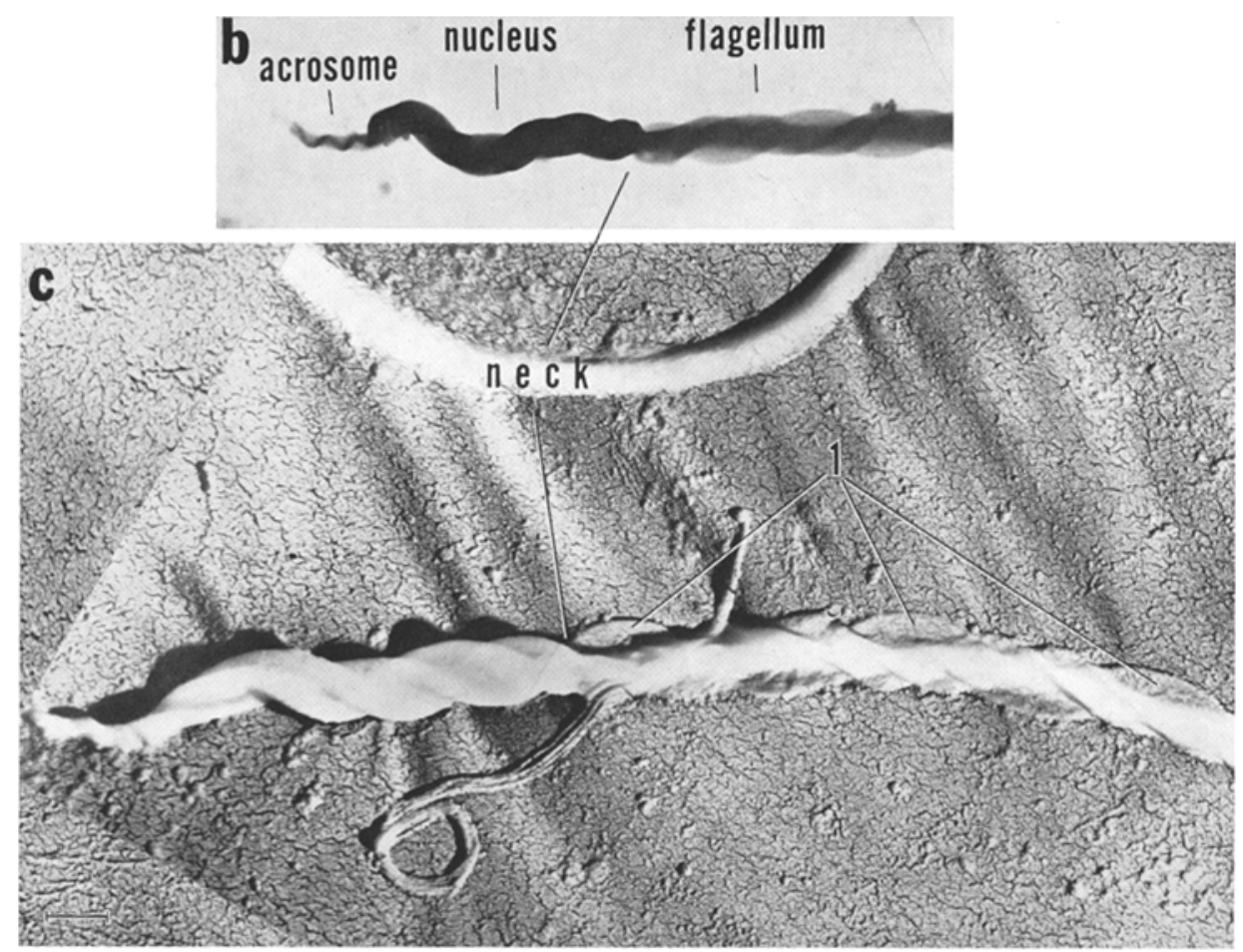

Fig. $2 \mathrm{~b}$ and c

stained by lead citrate (Fig. 4 b). In the base of the nucleus there is a pit $0.81 \mu$ deep in which the proximal centriole is situated and from which the axial fibres originate (Fig. 4a).

There appears to be no nuclear membrane present; neither does there appear to be an acrosomal membrane. The whole head is, however, covered by the same two-layered plasma membrane which encloses the whole cell. This membrane always appears to be wrinkled in sectioned material. Whole sperm do not give any indication of the surface wrinkling.

The acrosome. Cameron and Fogal (1963) pointed out that the structure of acrosomes varies widely from simple to complex. The acrosome of stylommatophoran sperm has a relatively simple morphology. In Agriolimax reticulatus sperm the anterior tip of the nucleus extends forward as a thin $(0.12 \mu$ wide) appendage about $2 \mu$ long (Fig. 2 b). The acrosome is deposited around this (Fig. 4 b) and is composed of a substance which appears granular in sections prepared for the electron microscope. There do not appear to be zones of different densities. Transverse sections through the acrosome show simply the nuclear extension excentrically surrounded by the granular acrosomal substance, and finally the plasma membrane. Gold-shadowed whole preparations show that the tip of the acrosome may be forked (Fig. 2a).

Flagellum. The flagellum or sperm tail is composed of the axial fibres $(9+2)$ and their mitochondrial sheath (Fig. 3). It is organized as follows. Centrally there 


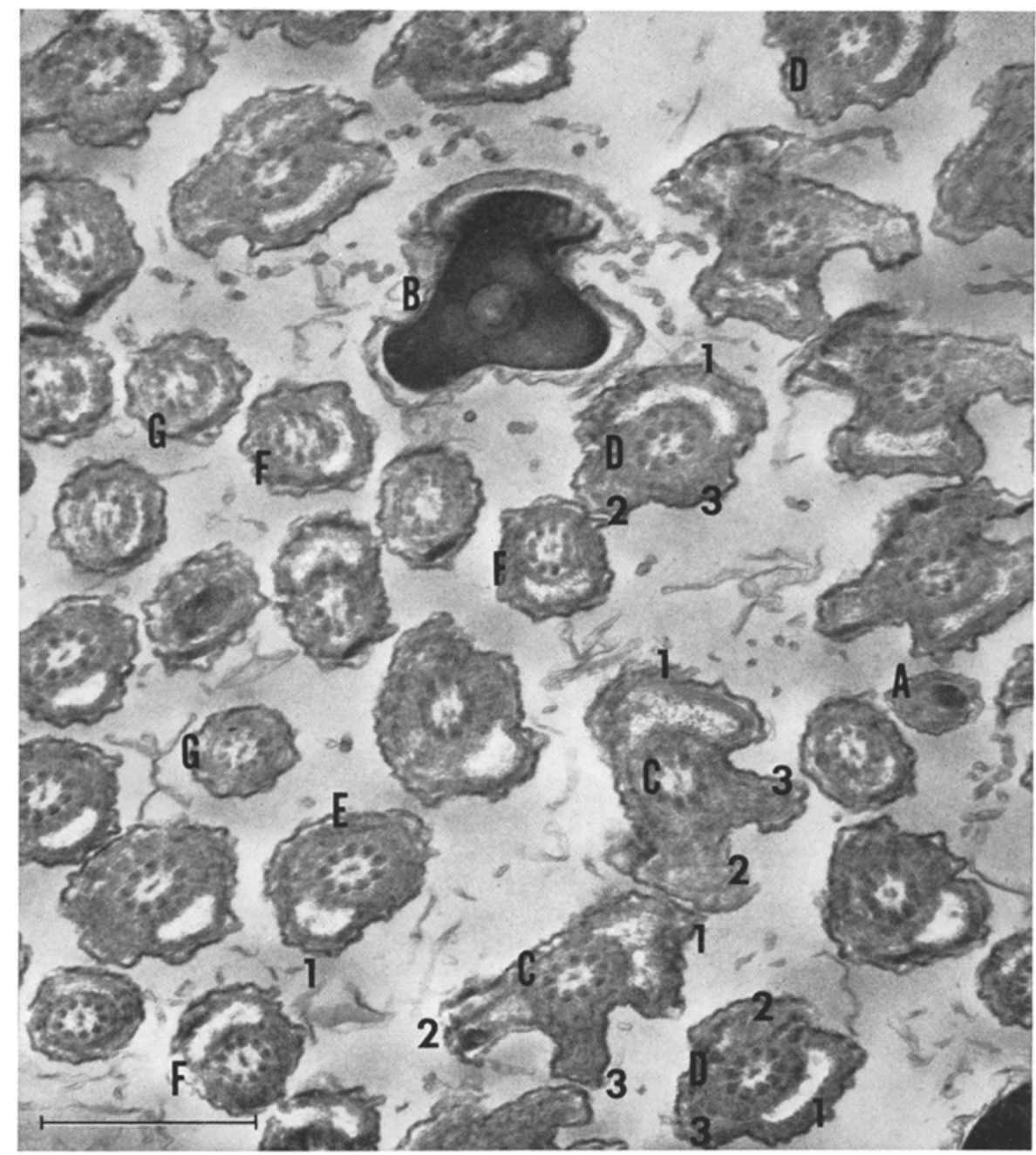

Fig. 3. Transverse sections through many different regions of spermatozoa. $A$ acrosome with dark excentric nuclear extension. $B$ base of head with "centriolar pit" showing. $C$ first part of flagellum where ridges 1,2 and 3 are high, and ridge 1 shows granular material. $D$ a little further back — ridges still prominent. $E$ towards middle of flagellum — ridge 1 still prominent. $F$ further back. $G$ towards posterior end of flagellum - the 2 mitochondrial layers are concentric, and are not separated by any spaces. Note the striated appearance of the mitochondrial derivative. Glutaraldehyde-Osmium. Uranyl acetate. Scale $=1$ micron

is an electron-transparent ground substance in which the central doublet runs longitudinally. Equally spaced around this are the nine peripheral fibres. Unlike the situation in some sperm tails (Afzelius, 1959), these nine fibres do not appear to differ from each other, and they are never clearly double. They also lack the electron-clear centres that are found in many other species. The fibres, like the nuclear material, are not stained by lead nor by potassium permanganate but 
are easily stained by uranyl acetate. It is almost certain that cross-links exist between the central and peripheral fibres, but longitudinal sections (Figs. 4a, 5) did not show their distribution clearly.

The axial fibre bundle is enclosed by a single membrane (Fig. 5). Immediately outside of this lies the periflagellar mitochondrial layer. In the first 8-10 $\mu$ of the flagellum, where ridges 2 and 3 are quite prominent (Fig. $2 \mathrm{c}$ ), this mitochondrial layer is thickened below the ridges, leaving a little space occupied by an apparently structureless substance between the two mitochondrial layers. Posteriorly this inner (periflagellar) mitochondrial layer is more evenly concentric, tightly enclosing the flagellar bundle. This layer is enclosed by a single membrane. The peripheral mitochondrial layer also has inner and outer membranes, and the inner one is separated from the outer membrane of the periflagellar sheath by a minimum spacing of $175 \AA$. This distance is greatly increased below ridge 1 (Fig. 3, $C-F$ ), which, as a helical canal, runs down the sperm tail to within $20 \pm 5 \mu$ of the tip. The lumen of this canal does not have its own limiting membrane. In material which has passed through glutaraldehyde during fixation (Fig. 3), a granular material is present in this lumen, just like the substance described by Personne and André as glycogen (1964).

Outside the peripheral mitochondrial sheath, which is of a more uniform width than the periflagellar sheath, the plasma membrane covers the cell.

The only other organelle in the sperm tail is a strange lamellar body (Figs. 6 and $4 \mathrm{~b}$ ) which is found in the lumen of helix 1 immediately behind the head and running back for $10 \pm 2 \mu$, the distance over which the ridges are particularly pronounced. This body starts as a ring of material in the "neck" region between the head and tail, where it surrounds the centriole. Over the first $2-3 \mu$ of the tail it fills the lumen of the helical canal, but it becomes thinner posteriorly and lines the centrifugal wall of the canal. Anteriorly it contains up to 20 electrondense parallel layers, but this number decreases to 4 or 5 near its posterior end. The layers or sheets are of constant thickness $-80 \AA-$ and appear to require lead staining or potassium permanganate in order to be made electron-dense. This lamellar body is comparable to a similar structure in the slug Testacella described by André (1962), but its origin and function are obscure. It is possible that it is a specialized mitochondrion which has not undergone the metamorphosis typical of most of the mitochondrial mass of pulmonate sperm tails (Grassé et al., 1956; André, 1962).

"Neck". Fig. 6 is the author's interpretation of the structure of this region. The centriolar pit is filled with an electron-opaque homogeneous substance, possibly serving to strengthen the head-tail junction. The presence of the lamellar body mentioned previously appears to be dependent, in addition to its staining properties, upon direct osmium fixation or potassium permanganate fixation, as its position is occupied by an electron-transparent area in material fixed with glutaraldehyde. Permanganate fixation slightly alters the appearance of this body.

The details of centriolar orientation and structure are not clear, and have not yet been clearly described in any sperm.

Some photographs, notably of spermathecal sperm (Fig. 4a), appear to show lateral striations in the axial bundle near the base of the head. 

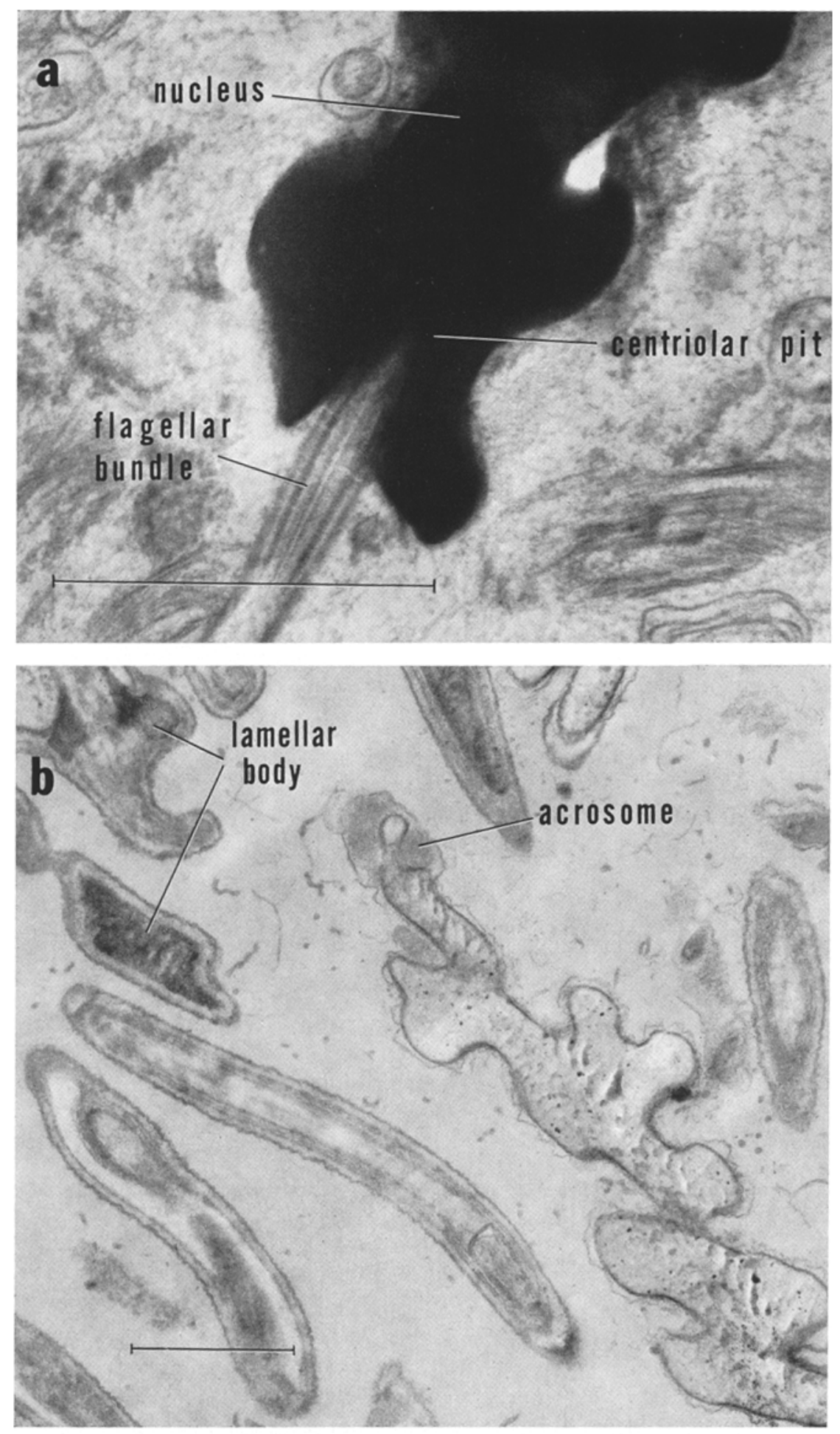

Fig. $4 \mathrm{a}$ and $\mathrm{b}$ 


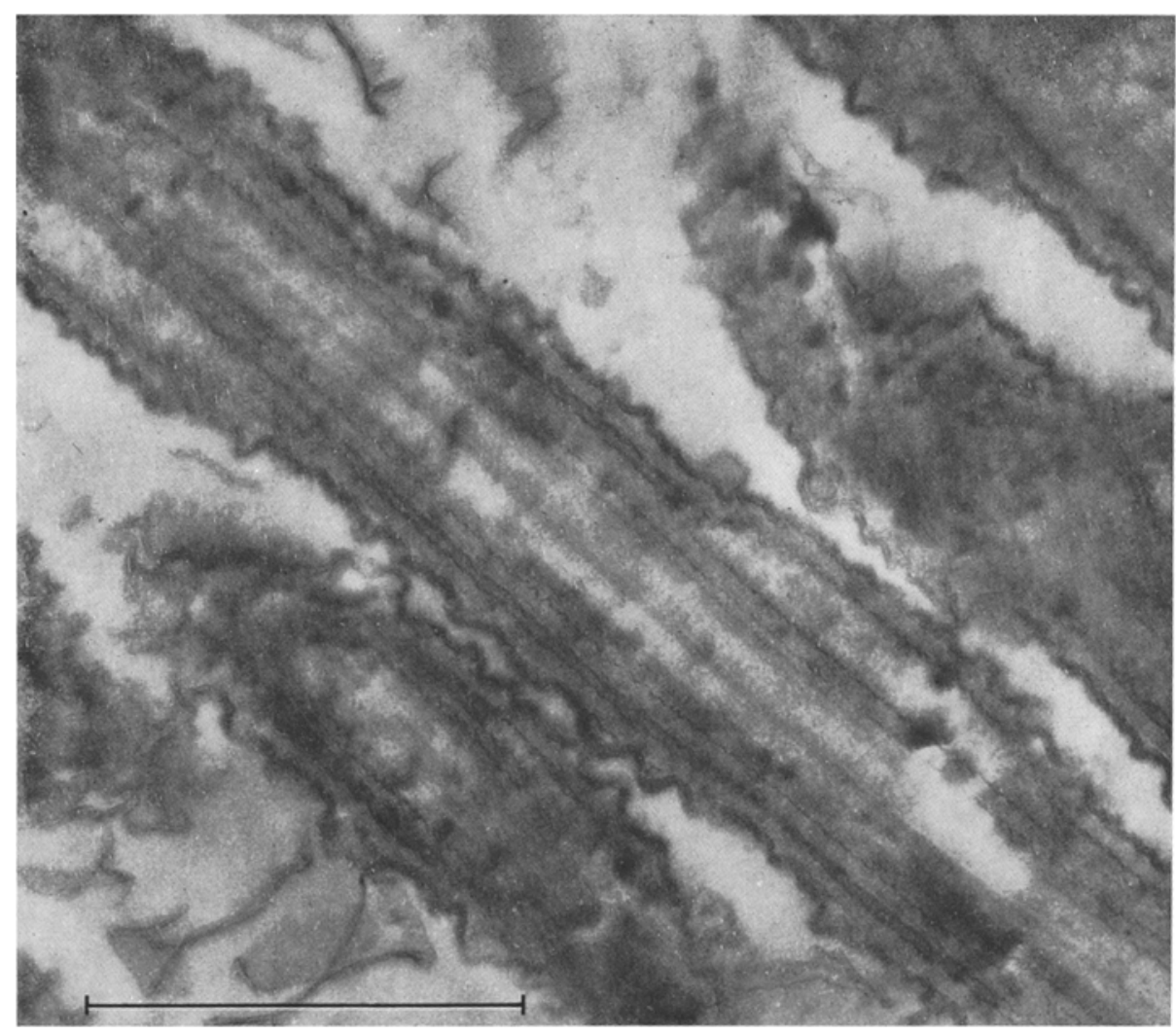

Fig. 5. Longitudinal section in the mid-region of the flagellum. Glutaraldehyde-Osmium. Lead citrate. This section was exposed to saliva at $37^{\circ} \mathrm{C}$ prior to being stained. Scale $=1$ micron

\section{Changes Occurring in the Spermatheca}

There has long been a lively controversy concerning the changes undergone by sperm in the pulmonate spermatheca (Ikeda, 1929; Ikeda and Mura, 1934; Perrot, 1939; de Larambergue, 1939; Bretschneider, 1948), and the importance of these changes to the physiology of the sperm. This controversy is still unresolved, probably due largely to the long-held assumption that sperm received at copulation all pass to the spermatheca.

Sperm in early stages of breakdown were found in sections of spermathecal contents in this study (Fig. 7). Due to the fact that such structures would be

Fig. 4. a Longitudinal section through the head of a sperm in the spermatheca or "gametolytic gland". The cell membrane and mitochondrial derivatives have been lost. The nucleus and flagellar bundle persist, and the centriolar pit is evident. The appearance of the flagellar bundle is indicative of the presence of radial structures. Osmium. Uranyl acetate. Scale $=$ 1 micron. b Longitudinal sections through sperm in the seminal vesicle. The base of the acrosome is visible at the top of the nucleus. The contour of the nucleus is noteworthy. The lamellar body shows in 2 sections of one sperm. Osmium. Lead citrate. Scale $=1$ micron 


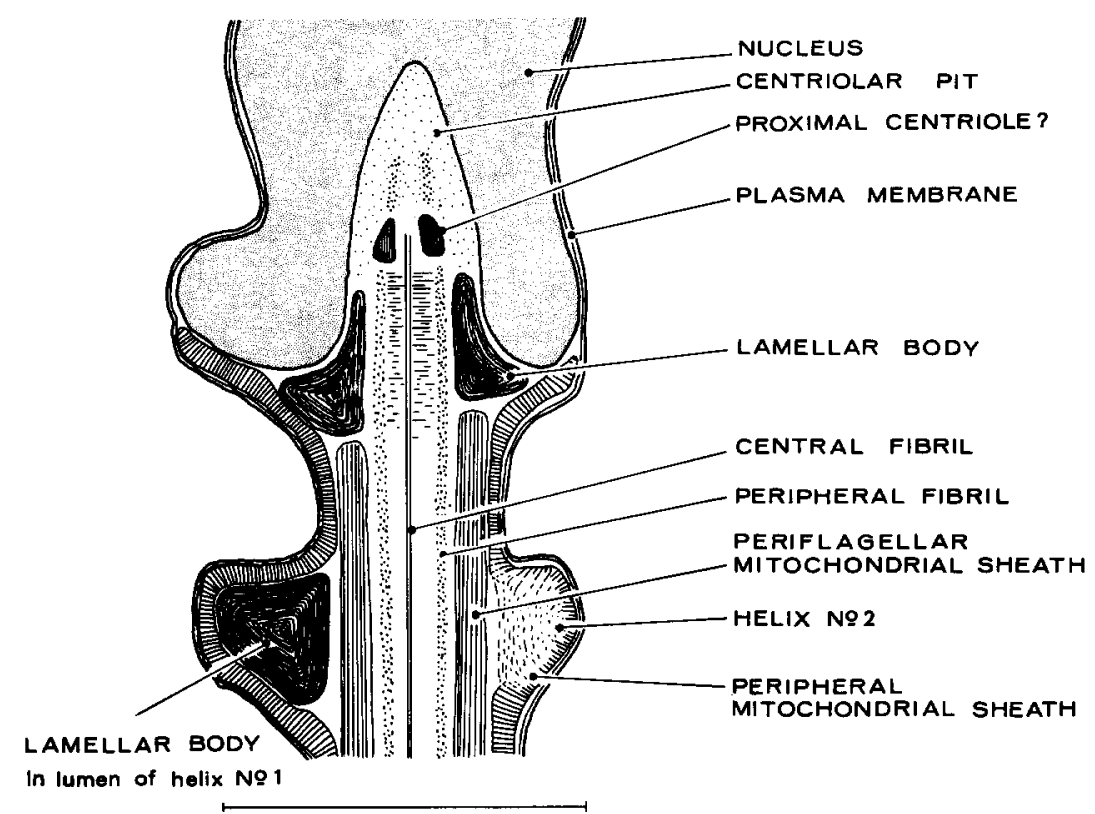

Fig. 6. Diagrammatic reconstruction of the neck region. Scale $=1$ micron

unrecognisable, it has not been possible to determine from electron micrographs whether a complete breakdown occurs.

The entire plasma membrane is lost. Acrosomal material is absent though the extension of the nuclear apex persists. The nucleus and 9 peripheral fibres of the axial bundle remain for the longest time, but whereas the nucleus maintains its normal shape, the axial fibres become disorientated relative to each other (though less so at the base of the head), and are almost certainly incapable of functioning. The mitochondrial sheath is soon lost, initially being reduced to numerous fine, longitudinal fibres.

The persistence of nuclear material agrees with light microscope observations which often show the presence of "sperm heads" in spermathecae of mature slugs.

Other contents indicate that the spermatheca is a "refuse container" for stray matter from the reproductive tract.

\section{Abnormalities}

Very few abnormalities have been seen.

In potassium permanganate fixed material certain cases were found where the plasma membranes of two sperm tails were fused, as reported by Tuzet and Galangau (1967).

One section of seminal vesicle spermatozoa contained an object apparently formed by the failure of 10 spermatids to separate prior to metamorphosis. Thus ten closely associated sperm tails have been cut in transverse section. 


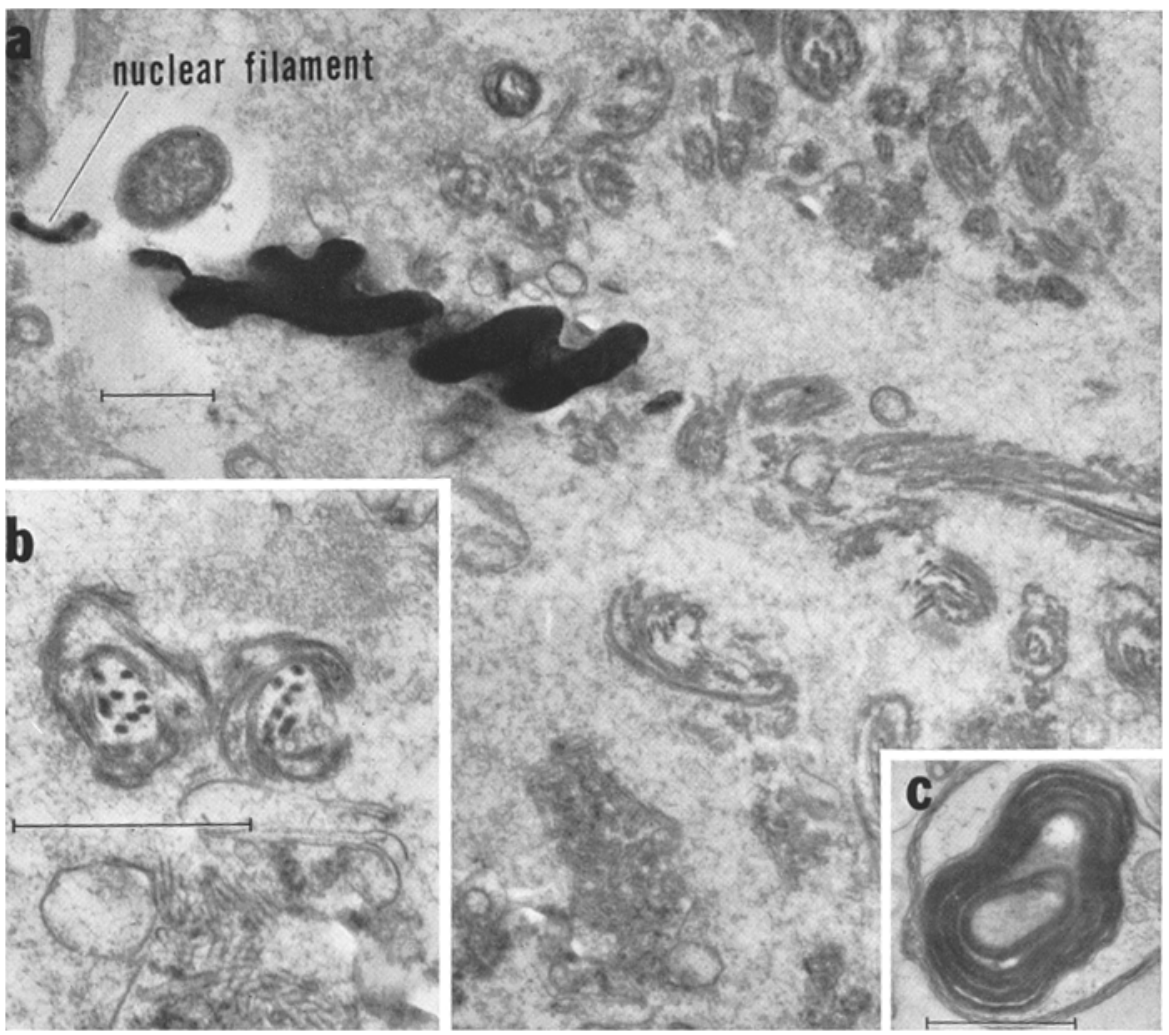

Fig. 7 a-c. Contents of the spermatheca. a The nuclear filament shows well. b Disorganized fibrils in flagella. c An example of many unidentified objects also present in the spermatheca.

Osmium. Uranyl acetate. Scale $=1$ micron

On one other occasion a photograph was obtained of a transverse section through a mature nucleus, around which was an abnormally loose membrane. This latter bore round objects on its outer surface rather like those reported by Grassé et al. (1956). The diameter of the nucleus indicated that this was either a very small sperm head - about half size - or that the section was of the front of the head just below the acrosomal level.

\section{Discussion}

The findings reported in this paper agree, in general, with other reports of pulmonate sperm structure (Grassé et al., 1956; Barth and Oliveira, 1964; Tahmisian, 1964). Unlike the situation in the majority of other taxa, the 9 peripheral fibres are singlets, not doublets. However, Bradfield (1955), working on this and other slugs, felt that the 9 peripheral fibres "probably" consisted of 2 subfibrils, but this was not illustrated in any micrographs. Gall's (1961) study of the prosobranch Viviparus and that of Walker and Macgregor (1968) on Thais (Nucella) lapillus both revealed 9 doublets, indicating that perhaps the orders Pulmonata 
and Prosobranchia differ in this respect. Thompson (1966, with Bebbington, 1969) has shown that in Opisthobranchs also, 9 peripheral doublets are present.

Agriolimax reticulatus and $A$. agrestis are very closely related species so that it is very unlikely that the structures of the spermatozoa differ in any marked way. Thus Tuzet and Sanchez (1950), restricted to the use of light microscopy, were probably mistaken in thinking that the head was given its spiral appearance by a superficial filament. The electron microscope clearly shows the complex corkscrew structure of the head. One other discrepancy with the earlier work on Agriolimax sperm (Tuzet and Sanchez, 1950) relates to the reported presence of a caudal filament posterior to the mitochondrial sheath. The electron microscope has now shown that a mitochondrial sheath covers the tail to its posterior extremity. This conforms with the typical structure for pulmonates (Franzen, 1956).

Fig. 3 shows that the mitochondrial material of the sperm tail has an internal structure different from that of typical mitochondria. The presence of equidistant, parallel layers seen here was reported also for the slug Testacella (André, 1962) and for Helix (Grassé et al., 1956; Tahmisian, 1964). In addition, the presence of 2 secondary and 1 main helicoidal ridge along the sperm tail was also reported for Testacella (André, 1962).

During the period of this study Tuzet and Galangau (1967) published on the ultrastructure of the Agriolimax sperm tail. The authors arrived at conclusions concerning the structure of the helix which differ from my conclusions. These differences are, in my opinion, due to differences in interpretation. Having studied both whole and sectioned sperm in the E.M. I am confident that the structure I propose is correct. Some other differences are, however, genuine, such as the absence from $A$. reticulatus spermatozoa of peripheral microtubules and of elastic fibres. These differences may possibly be explained by the source of material. I studied sperm from the seminal vesicles where spermatozoa are stored after their maturation in the gonad; micrographs published by Tuzet and Galangau clearly indicate that the material they studied was not solely mature sperm. It is my opinion that although Grassé et al. (1956) have also reported the presence of peripheral microtubules, these elements are not typical of fully mature pulmonate sperm. The importance of using the seminal vesicle when one desires mature spermatozoa should be emphasized.

It is interesting to consider the complexity of the flagellar structure in light of the ecology of the sperm (Franzen, 1955). In reproductive systems of pulmonates there are well developed prostate glands, and copulation ensures that sperm are deposited well inside the reproductive tract of a partner. Ciliary and muscular mechanisms which are present within these tracts may facilitate the movement of sperm to the site of fertilization. Yet the structural complexity of the sperm flagellum is as great or greater than that of sperm flagella from molluses which release their sperm into the environment (Franzen, 1955). This difference can be taken as indicative of the high degree of efficiency such "external fertilizers" may achieve in bringing sperm and eggs close together without the active participation of the sperm.

Whereas the sperm tail in copulating molluses generally appears more complex than that in non-copulating molluses, e.g., bivalves, the structure of the acrosome seems to be, in contrast, more simple. The beautiful work of Thompson and 
Bebbington (1969) with the opisthobranch slug Aplysia, revealed no acrosome on the sperm head, and those authors point out that with internal fertilization in which the sperm are brought into direct contact with the egg cell membrane, no complex acrosome need be postulated. The circumstances in which fertilization occurs in pulmonates is thought to be similar to those in opisthobranchs, yet a relatively simple acrosome is certainly present in Agriolimax. At this point several mistaken claims in Thompson and Bebbington's paper (1969) should be corrected. The authors state that "the spermatozoon of Aplysia is inlike that of any other molluse so far described in the following respects: (a) the presence of 2 mitochondrial strands, of disparate sizes, forming alternating helices extending over the majority of the length of the cell; (b) the helical disposition of the nucleus; (c) the extension of the flagellum into the centre of the nuclear helix so that it reaches almost to the front tip of the gamete." With reference to (a) Anderson and Personne (1969 b) have described a "principal helix" and a "secondary helix" of mitochondrial derivative along the sperm tail of Helix, and Barth and Oliveira (1964) referred to "two helicoidal fibrils of mitochondrial origin" along the sperm flagellum of Biomphalaria glabrata. With reference to (b) Karpevich (1961) illustrated several helical sperm heads in bivalves, von Siebold (1836) described a twisted head for Viviparus, a prosobranch, and Kaye (1958) referred to the spiralling of the sperm nucleus of Viviparus. Furthermore, Rebhun (1957) described the "twisting" of the sperm head of the pulmonate Otala, and Watts (1952) reported that on reaching maturity the sperm head of Helix becomes a corkscrew. Finally, with reference to (c) Walker and Macgregor (1958) gave illustrated confirmation of an earlier report that the flagellum of the Thais (Nucella) lapillus spermatozoon extends to the anterior portion of the nucleus, very close to the base of the acrosome. Also, Hickman (1931) described both an intranuclear rod and a spiral head and tail for the spermatozoon of Succinea ovalis. These oversights do not materially detract from an excellent piece of work by Thompson and Bebbington. They propose the term "gametolytic gland" for the "spermatheca" of Aplysia; similarities in their and my observations indicate that at least part of the functions of the Agriolimax "spermatheca" is truly gametolytic. Surprisingly, in the opisthobranch the sperm nuclei were digested before the flagella.

In Agriolimax the condition of the spermathecal sperm indicates their uselessness in fertilization. This adds weight to the theory that sperm received at copulation, if passed to the spermatheca, do not remain there long; they must be stored elsewhere during the period - which may be several weeks - between copulation and fertilization, unless the nature of the spermathecal contents is very different during that period.

Such questions as the relation of the mitochondrial sheath to the physiology of the sperm, the mechanisms of movement of the tail, the absence or presence and identity of a respiratory substrate within the main helix, the role of the acrosome and other parts in fertilization, the contribution of sperm material to the zygote, the significance of the spirals, the nature of the lamellar body, and the exact structure of the centrioles and neck, are important and interesting. Further studies are needed in order that profitable discussion can be undertaken of the functional physiology of the spermatozoon. 


\section{References}

Afzelius, B. A.: Electron microscopy of the sperm tail. Results obtained with a new fixative. J. biophys. biochem. Cytol. 5, 269-278 (1959).

Anderson, W. A., Personne, P.: Structure and histochemistry of the basal body derivative, neck and axoneme of spermatozoa of Helix aspersa. J. Microse. 8, 87-96 (1969a).

- - The cytochemical localization of sorbitol dehydrogenase activity in spermatozoa of Helix aspersa. J. Microse. 8, 97-102 (1969b).

André, J.: Contribution à la connaissance du chondriome. Etude de ses modifications ultrastructurales pendant la spermatogénèse. J. Ultrastruct. Res., Suppl. 3, 1-185 (1962).

Barth, R., Oliveira, F. B.: Submicroscopic structure of the sperm flagellum of Triatoma infestans and Australorbis glabratus. An. Acad. bras. Ci. 36, 559-564 (1964).

Bayne, C. J.: Studies on the composition of extracts of the reproductive glands of Agriolimax reticulatus, the grey field slug (Pulmonata, Stylommatophora). Comp. Biochem. Physiol. 23, $761-773$ (1967).

Bradfield, J. R. G.: Fibre patterns in animal flagella and cilia. Symp. Soc. exp. Biol. 9, $306-334(1955)$.

Bretschneider, L. H.: Insemination in Lymnaea stagnalis L. Proc. kon. ned. Akad. Wet. 51, 358-363 (1948).

Cameron, M. L., Fogal, W. H.: The development and structure of the acrosome in the sperm of Lumbricus terrestris L. Canad. J. Zool. 41, 735-761 (1963).

Franzen, $\AA$.: Comparative morphological investigations into the spermiogenesis among mollusca. Zool. Bidrag. Uppsala 30, 399-456 (1955).

- On spermiogenesis and morphology of the spermatozoon, and biology of fertilization among invertebrates. Zool. Bidrag. Uppsala 31, 355-482 (1956).

Galangau, V., Tuzet, O.: Cou et présence des formations de nature ergastoplasmique dans les spermatides de Milax gagates Drap. (Gastéropode Pulmoné). C. R. Acad. Sci. (Paris) D 262, 2364-2366 (1966).

Gall, J. G.: Centriole replication. A study of spermatogenesis in the snail Viviparus. J. biophys. biochem. Cytol. 10. 163-193 (1961).

Grassé, P. P., Carasso, N, Favard, P.: Les ultrastructures cellulaires au cours de la spermiogénèse de l'escargot (Helix pomatia $\mathrm{L}$.): évolution des chromosomes, du chondriome, de l'appareil de golgi, etc. Ann. Sci. nat. Zool. 18, 339-380 (1956).

Hickman, C.P.: The spermiogenesis of Succinea ovalis Say. with special reference to the components of the sperm. J. Morph. 51, 243-289 (1931).

Ikeda, K.: The spermatozoa of Philomycus bilineatus with special reference to their metamorphosis in the receptaculum seminis. Annot. zool. jap. 12, 295-321 (1929).

- Mura, S. E.: On the possibility of self-fertilization and longevity of spermatozoa in the receptaculum seminis in the land snail Bradybaena similaris stimpsoni. Venus 4, 208-224 (1934).

Karpevich, A.F.: Adaptive character of spermatozoa and egg morphology in Bivalviamollusca. [In Russian.] Zool. Zh. 40, 340-350 (1961).

Kay, D. H.: Techniques for electron microscopy, 2nd ed. Oxford: Blackwell Sci. Publ. 1965.

Kaye, J. S.: Changes in the fine structure of mitochondria during spermatogenesis. J. Morph. $102,347-400(1958)$.

Larambergue, M. de: Etude de l'autofécondation chez les gastéropodes pulmonés. Recherches sur l'aphallie et la fécondation chez Bulinus (Isidora) contortus (Michaud). Bull. Biol. 73, 19-231 (1939).

Pasteels, J. J.: La fécondation étudiée au microscope électronique. Etude comparative. Bull. Soc. zool. France. 90, 195-224 (1965).

Pease, D. C.: Histological techniques for electron microscopy, 2nd ed. London: Academic Press 1964.

Perrot, J.-L.: Contribution à l'étude de la fécondation chez les pulmonés stylommatophores. Le cas de l'Arion empiricorum Fer. (Arion rufus L). Bull. Biol. 73, 408- 432 (1939).

Personne, P., Anderson, W. A.: Compartimentage des activités enzymatiques dans le spermatozöide de certains mollusques gastéropodes. I. Localisation des déshydrogénases. J. Cell Sci. 4, 693-708 (1969).

- André, J.: Existence de glycogène mitochondrial dans le spermatozoïde de la Testacelle. J. Microsc. 3, 643-650 (1964). 
Rebhun, L. I.: Nuclear changes during spermiogenesis in a pulmonate snail. J. biophys. biochem. Cytol. 3, 509-524 (1957).

Siebold, C. T. von: (referred to in Walker and Macgregor 1968). Fernere Beobachtungen über die Spermatozoen der wirbellosen Thiere. Arch. Anat. Physiol. 232-255 (1836).

Tahmisian, T. N.: On orderly domains of particles associated with cytomembranes during spermatogenesis in Helix aspersa. Z. Zellforsch. 64, 25-31 (1964).

Thompson, T. E.: Studies on the reproduction of Archidoris pseudoargus (Rapp) (Gastropoda Opisthobranchia). Phil. Trans. B 250, 343-375 (1966).

- Bebbington, A.: Strueture and function of the reproductive organs of three species of Aplysia (Gastropoda: Opisthobranchia). Malacologia 7, 347-380 (1969).

'Tuzet, O., Galangau, V.: Ultrastructure de la "membrane ondulante» d'Agriolimax agrestis L. C. R. Acad. Sci. (Paris) D 264, 337-339 (1967).

- Sanchez, S. : La spermatogénèse des Limaces Milax gagates Drap. et Agriolimax agrestis L. Ann. Sci. Nat. Zool. 12, 303-308 (1950).

Walker, M., Macgregor, H. C.: Spermatogenesis and the structure of the mature sperm in Nucella lapillus (L.). J. Cell Sci. 3, 95-104 (1968).

Watts, A. H. G.: Spermatogenesis in the slug Arion subfuscus. J. Morph. 91, 53-78 (1958).

Yasuzumi, G.: Spermatogenesis in animals as revealed by electron microscopy. XII. Light and electron microscope studies on spermiogenesis of Cipangopaludina malleata Reeve. J. Ultrastruct. Res. 7, 488-503 (1962).

Dr. Christopher J. Bayne

Museum of Zoology

University of Michigan

Ann Arbor, Michigan 48104 (U.S.A.) 